Article available at http://www.parasite-journal.org or http://dx.doi.org/10.1051/parasite/1994074291

\title{
Parasitic effects ON hOST life-hISTORY tRaits : A REVIEW OF RECENT STUDIES
}

\author{
MICHALAKIS Y.* AND HOCHBERG M. E.**
}

\section{Summary :}

We review empirical studies bearing on the effects of parasites on the age of maturity of their hosts. The few cases already published support theoretical predictions, namely a decrease of host prereproductive life-span unless parasites are benign. Host responses may be due either to phenotypic plasticity or to genetic differences, and even though very few studies on this topic have already been published both mechanisms occur. Promising areas of research include the distribution of age-specific potential costs of resistance to parasitism, as well as the evolution of age-specific parasite preferences under the concomitant evolution of host lifehistory traits.

KEY WORDS : host-parasite interactions. life-history evolution. age at maturity. MOTS CLES : interactions hôtes-parasites. évolution des traits biodémographiques. âge à la maturité.
Résumé : EFFETS DES PARASITES SUR LES TRAITS BIODÉMOGRAPHIQUES DE LEURS HOTES : UNE REVUE DES ÉTUDES RÉCENTES

Nous proposons une revue des études portant sur les effets des parasites sur l'âge de maturité de leurs hôtes. Les quelques études publiées confirment des prédictions théoriques, en particulier un délai de la maturité de l'hôte dans la majorité des cas sauf lorsque les parasites sont bénins. Les réponses des hôtes aux parasites peuvent être expliquées ou bien par une plasticité phénotypique ou bien par des différences génétiques, les deux types de mécanismes ayant été rencontrés bien que très peu d'études aient abordé ce sujet. Des champs de recherche prometteurs seraient la distribution en fonction de l'âge de l'hôte d'éventuels coûts de résistance aux parasites, ainsi que l'évolution des préférences parasitaires pour des hôtes d'âge donné sous l'évolution concomitante des traits biodémo. graphiques des hôtes.

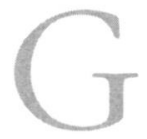
iven the fundamental importance of life-history theory to evolutionary biology it is somewhat surprising that applications to host-parasite systems have only started to appear over the past decade, and are almost all empirical (Minchella, 1985; Thornhill et al., 1986). Rather, most research involving the evolution of host-parasite systems has been concerned with changes in parasite virulence, developments being both empirical and theoretical (for reviews see May and Anderson, 1990; Toft and Karter, 1990).

Recently, Hochberg et al. (1992) investigated in detail with the aid of a mathematical model just how parasites could affect the most fundamental of their host's life-history traits, the time to first reproduction (Promislow and Harvey, 1990). They showed that hosts subjected to virulent parasites and unable to resist by other means [e.g. immunological resistance (Klein, 1982) or inducible defenses (Harvell, 1990 a,b)] would be favoured by selection if they were able to reproduce earlier. Only in cases where para-

\footnotetext{
* Institut d'Écologie CNRS URA 258, ENS, Université P. et M. Curie, Bât. A 7 e ét. CC 237, 7 quai St. Bernard, 75252 Paris Cedex 05, France.

** Institut d’Écologie CNRS URA 258, Université P. et M. Curie, ENS, 46 rue d'Ulm, 75230 Paris Cedex 05, France.
}

sites were relatively benign could parasitism select for longer pre-reproductive life spans.

Here we review empirical evidence relating to the theoretical propositions of Hochberg et al. (1992). We address two principal questions. First, whether their predictions have been met and, second, whether the responses of the hosts to parasitism are attributable to phenotypic plasticity or rather to genetic differentiation. In addressing these questions we examine analogous examples involving prey-predator interactions. After discussing the evidence, we propose several directions for further research. We emphasize that the experimental literature on effects of parasites on host life-history traits is still in its infancy, and therefore it is too early to reach firm conclusions. The few experiments discussed, however, show that this research area is promising.

\section{PRE-REPRODUCTIVE LIFE SPAN}

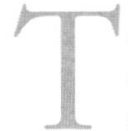
o our knowledge three experimental studies closely related to this topic have been published recently in the primary literature. Interestingly, these studies have expanded the taxonomic range of organisms usually covered in life-his- 
tory investigations; virtually all past studies have concerned snails as hosts to parasitic worms (see reviews in Minchella, 1985; Michalakis et al., 1992). Indeed, we start by reviewing a case involving a snail and its trematode parasites.

Lafferty (1993) studied the interaction between the marine snail Cerithidea californica and several trematodes which parasitise it. He attempted to test whether parasitism affects age at maturity of these snails. He was unable to study directly age at maturity, instead measuring size at maturity, under the assumption that size is highly correlated to age in these organisms. He showed that there was a negative correlation between size at maturity and the level of infestation of the host population. In other words, snails matured significantly earlier in populations subjected to high parasitism. Using transplant experiments, he showed that there was a significant effect of the origin of the population. This result indicates some genetic basis for the response of the hosts, though it does not preclude other environmental factors such as maternal effects.

Gomariz-Zilber and Thomas-Orillard (1993) studied the interaction between Drosophila melanogaster and its picornavirus (the "C virus"). Infection by this pathogen induces relatively high pre-adult mortality (as much as $40 \%$ ). They showed, however, that infected flies have a significantly decreased developmental time (from egg to adult), developmental time being influenced by temperature, origin of the population, and the viral dose applied to the host population. Because temperature was responsible of about $98 \%$ of the total variance, the authors performed separate analyses at the two different temperatures assayed. At $25^{\circ} \mathrm{C}$, developmental time significantly decreased in all three populations studied, each showing a roughly similar pattern (no population effect). At $20^{\circ} \mathrm{C}$, however, the results depended on the population studied since, in some populations, development was accelerated as viral dose increased while, in others, development was retarded. Interestingly the authors also showed that infection by the C-virus increased the mean number of ovarioles for all populations at both temperatures.

Boots and Begon (1993) studied the interaction between the Indian meal moth (Plodia interpunctella) and a granulosis virus. They were able to select strains which were resistant to the virus, the rate of resistance being 1.96 times that of the susceptible base population. This resistance carried an associated cost, however, corresponding to an increase in developmental time, a reduction in egg-viability and an increase in pupal weight. The authors further dissected the nature of the cost and found that development was delayed only in the fourth and fifth larval instars. The authors noted that these moths are susceptible to infection only during the first three instars, while they are practically immune during the fourth and fifth instars. In other words, resistance to parasitism causes a delay of age at maturity. This delay, however, does not concern the susceptible host stages but only stages which are immune.

\section{ANALOGY TO PREDATION}

everal analogous studies on life-history shifts have been conducted in predator-prey interactions (reviewed in Lafferty, 1993). Some have shown that under strong predator pressure, prey reduce their pre-reproductive life-span (e.g. Reznick et al., 1990). More interestingly, the effect of predators on prey life-history strategies depends on agespecific predation rates. For example, Reznick et al. (1990) showed that guppies mature earlier when attacked as adults rather than as juveniles. A longterm experiment by the same group showed that these differences have a genetic basis.

There exist several other cases where pre-reproductive life-span is increased by predators and in all of them the delay is related to a higher susceptibility of early life stages. For example, Crowl and Covich (1990) showed that the freshwater snail Pbysella virgata virgata increases its growth rate and delays maturity in the presence of a predator crayfish (Orconectes virilis). This delay in maturity can be explained by the fact that the predators preferentially eat small sized prey, so that there is strong selection pressure among the snail population to divert resources to growth in order to reduce the duration of the stage susceptible to predation. Crowl and Covich (1990) were furthermore able to show that this shift was due to phenotypic plasticity of the snails, rather than to fixed genetic differences.

\section{PHENOTYPIC PLASTICITY OR GENETIC DETERMINISM?}

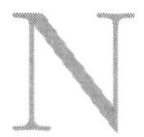

ot surprisingly, evidence on this topic is even more scanty than for the previous two. The few cases available, however, show that both types of determinism exist in natural systems. Cases of infection of snails by schistosomes (reviewed in Minchella, 1985 and Michalakis et al., 1992) indicate that the host response is due to phenotypic plasticity. The same is true for the response of the snail $P$. virgata subjected to predation by crayfish (Crowl and Covich, 1990). The decrease of maturation size of the snail C. californica when parasitised 
by trematodes (Lafferty, 1990) depends on the origin of the population. This latter result does not exclude that other factors, such as maternal effects, might be responsible for these differences.

In other cases there is certainly a genetic basis in the host reaction. For example, the resistance and associated developmental delay of the Indian meal moth to granulosis virus is definitely due to genetic differences among strains (Boots and Begon, 1993). There must also be some genetic basis in the reaction of Drosophila populations to infection by C-virus, since at least at some temperatures the various strains react differently (some increase and some decrease their developmental time; Gomariz-Ziber and ThomasOrillard, 1993). Finally, Reznick et al. (1990) clearly showed that the response of guppies to different kinds of predators has a genetic basis.

The small number of case studies does not enable us to distinguish any clear trends. One potential guide could be the predictability of the infection (or predation). Indeed, it seems reasonable to expect a phenotypically plastic response whenever the parasite (or predator) pressure is highly unpredictable in space and/or in time. In such instances, a genetic basis would not readily evolve, because the selection pressure imposed by the parasites could be absent or highly variable in direction. For example, if parasites specifically attacking early larval instars are present only during several generations and then replaced by parasites preferentially attacking adults one would expect any reaction evolved by the hosts to be plastic. Genetic determinism would be reasonable in those cases where the trend of the selection pressure imposed by parasites is relatively constant through time.

From the few cases studied so far, we know that parasitism levels are generally weak among snail populations and highly variable through time (Anderson and May, 1979). In agreement with our verbal argument the responses of snails to parasitism are plastic (Minchella, 1985; Michalakis et al., 1992). On the other hand, the predation pressure exerted on guppies seems to have consistent trends through time, giving sufficient time for genetically-based prey reactions to evolve (Reznick and Endler, 1982; Reznick et al., 1990).

\section{PERSPECTIVES FOR FUTURE RESEARCH}

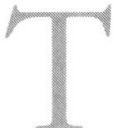

he predictions of Hochberg et al. (1992) are generally met in the few cases published so far. The exceptions come from factors they did not model. These are the existence of other modes of resistance and age-specific parasite infection.
In the first case, Boots and Begon (1993) showed that in the presence of resistance, associated costs should be distributed across stages in such a way that the costs are preferentially carried by stages immune to parasitism. Resistance is expected to have associated costs because, otherwise, all individuals would be expected to be resistant (unless the observed polymorphism is transient; see Frank, 1992, for a discussion of this topic in the case of plant-pathogen interactions). As far as we know, this research area is totally open both theoretically and experimentally. It would indeed be very interesting to look at the way resistance costs are distributed across age (or stage) classes in relation to age (or stage) specific parasitism rates.

The age-specificity of parasitic infestation (or predator attack) seems to be a very important parameter in the evolution of hosts subjected to parasitism. Hosts preferentially attacked at young ages would evolve towards delayed maturation, while hosts attacked at late ages should evolve towards accelerated maturation. This result of life-history theory (see Stearns, 1992 for a review) is, so far, corroborated by all studies of which we know. It has not been formalised though in the context of host-parasite interactions. More importantly, it would be interesting to investigate how parasite age-specific preferences should evolve under the concomitant evolution of host lifehistory traits.

The outcome of these interactions is more complicated if the differential parasitism effects are stagedependent and fecundity increases with body size as is the case for many organisms. If the adult stage is parasitised preferentially while fecundity increases with body size, maturity is expected to be delayed. This is because animals which will stay longer in the parasite-immune larval stages will have larger adult body sizes and therefore a higher potential fecundity if they can escape parasitism (reviewed by Roff, 1992, p. 197).

The determinism of the host reaction to parasite attack is still a matter of debate. Both phenotypic plasticity and genetic determinism have been found in experimental cases. It would be interesting to relate the nature of the determinism of the host reaction to the predictability of the direction of the parasite pressure. This area of research is still virtually devoid of detailed data.

Finally, it would be interesting to compare the fitness of hosts which modify their behaviour after parasitism, not only to hosts which do not modify theirs but also to unparasitised hosts. Indeed, it has been proposed that parasites could actually avoid an arms race with their host if they were pleitotropic with respect to their host's fitness (Michalakis et al., 1992). 
The term " pleiotropy ", used as an analogy to developmental genetics, means that a given factor might have various effects. In the present context, a parasite could have both benign and detrimental effects. The two kinds of effect could be manifested under different conditions either in space (spatial pleiotropy) or in time (temporal pleiotropy). As an extreme case, parasites could act like senescence genes (sensu Williams, 1957) with beneficial effects at early stages in the life of the host and detrimental effects at later stages.

\section{REFERENCES}

Boots M. and Begon M. Trade-offs with resistance to a granulosis virus in the Indian meal moth, examined by a laboratory evolution experiment. Functional Ecology, 1993, 7, 528-534.

Crowl T.A. and Covich A.P. Predator-induced life-history shifts in a freshwated snail. Science, 1990, 247, 949-951.

Frank S.A. Models of plant-pathogen coevolution. Trends in Genetics, 1992, 8, 213-219.

Gomariz-Zilber E. and Thomas-Orillard M. Drosophila C virus and Drosophila hosts : a good association in various environments. Journal of Evolutionary Biology, 1993, 6, 677-689.

Harvell C.D. The ecology and evolution of inducible defenses. Quartely Review of Biology, 1990a, 65, 323-340.

Harvell C.D. The evolution of inducible defenses. Parasitology, 1990b, 100, S53-S61.

Hochberg M.E., Michalakis Y. and de Meeds T. Parasitism as a constraint on the rate of life-history evolution. Journal of Evolutionary Biology, 1992, 5, 491-504.

Jeune B. and Thomas-Orillard M. Beneficial effects of viral infection in Drosophila : an evolutionary model. Acta Oecologia, 1991, 12, 489-508.

KLEIN J. Immunology: the science of self-non-self discrimination. Wiley Interscience, NY, 1982.

LAFFERTY K.D. The marine snail, Cerithidea californica, matures at smaller sizes where parasitism is high. Oikos, 1993, 68, 3-11.

MAY R.M. and Anderson R.M. Parasite-host coevolution. Parasitology, 1990, 100, S89-S101.

Michalakis Y., Olivieri I., Renaud F. and Raymond M. Pleiotropic action of parasites : how to be good for the host. Trends in Ecology and Evolution, 1992, 7, 59-62.

Minchella D.J. Host life-history variation in response to parasitism. Parasitology, 1985, 90, 205-216.

Promislow D.E.L. and Harvey P.H. Living fast and dying young : a comparative analysis of life history variation among mammals. Journal of the Royal Society of London, 1990, 220, 417-437.

Reznick D.A. and Endler J.A. The impact of predation on life-history evolution in trinidadian guppies (Poecilia reticulata). Evolution, 1982, 36, 160-177.
Reznick D.A., Bryga H. and Endler J.A. Experimentally induced life-history evolution in a natural population. Nature, 1990, 346, 357-359.

RofF D.A. The evolution of life histories. Theory and analysis. Chapman and Hall, New York, 1992.

STEARNS S.C. The evolution of life-histories. Oxford University Press, Oxford, 1992.

Thornhill J.A., Jones T., and Kusel K.R. Increased oviposition and growth in immature Biomphalaria glabrata after exposure to Schistosoma mansoni. Parasitology, 1986, 93, 443-450.

Toft C.A. and Karter A.J. Parasite-host coevolution. Trends in Ecology and Evolution, 1990, 5, 326-329. 